Estudios Constitucionales, Año 15, № 2, 2017, pp. 301-330

ISSN 07180105

Centro de Estudios Constitucionales de Chile Universidad de Talca

"La influencia europea en el ámbito de los derechos fundamentales en España, en concreto, en el derecho a la intimidad"

Ángela Moreno Bobadilla

\title{
LA INFLUENCIA EUROPEA EN EL ÁMBITO DE LOS DERECHOS FUNDAMENTALES EN ESPAÑA, EN CONCRETO, EN EL DERECHO A LA INTIMIDAD*
}

\author{
THE EUROPEAN INFLUENCE IN THE FRAMEWORK OF FUNDAMENTAL RIGHTS IN \\ SPAIN, IN CONCRETE IN THE RIGHT TO INTIMATE \\ Ángela Moreno Bobadilla* \\ Universidad Central de Chile. \\ angela.moreno@ucentral.cl
}

RESUMEN: El derecho a la intimidad en España hay que examinarlo desde un triple punto de vista: el del Consejo de Europa, el de la Unión Europea, asi como el de los ordenamientos jurídicos nacionales. Estos sistemas de derechos fundamentales se encuentran interrelacionados entre sí, habiéndose generado un diálogo entre tribunales, asi como modificaciones del contenido de este derecho fundamental susceptible de protección dentro del ordenamiento jurídico español.

ABSTRACT: The right to privacy in Spain must be examined from a triple point of view: that of the Council of Europe, that of the European Union, as well as that of national legal systems. These systems of fundamental rights are interrelated with each other, creating a dialogue between courts, as well as changes in the content of this fundamental right that can be protected inside of the legal order Spanish.

PalabRas Clave: Derecho a la intimidad, Derecho europeo, Tribunal Europeo de Derechos Humanos, Tribunal de Justicia de la Unión Europea, ordenamiento jurídico español.

KEYWORDS: Right to privacy, European law, European Court of Human Rights, Court of Justice of the European Union, legal order Spanish.

\section{INTRODUCCIÓN}

La construcción jurídica actual del derecho a la intimidad en España se ha visto dominada directamente por el derecho europeo como consecuencia

\footnotetext{
* Trabajo recibido el 17 de diciembre de 2017 y aprobado el 30 de agosto de 2017.

** Directora del Área de Derecho Público de la Universidad Central de Chile. Doctora en Derecho (Suma Cum Laude) por la Universidad Complutense de Madrid. Abogada por la UNED y Licenciada en Periodismo por la Universidad Complutense de Madrid. Imparte docencia en las cátedras de Derechos Fundamentales, Seminario de Tesis y Derecho Internacional Público. Sus líneas de investigación principales son los derechos fundamentales dentro de los ordenamientos jurídicos trasnacionales, así como los derechos de la infancia. Es miembro de la Asociación de Constitucionalistas de España.
} 
de la influencia directa que éste ostenta dentro de los ordenamientos jurídicos nacionales.

El derecho fundamental a la intimidad ha evolucionado desde que se produjo la promulgación de la Constitución Española (a partir de ahora CE) en 1978 hasta la fecha. Se ha convertido en un derecho sólido y consolidado, que cuenta con un delimitado objeto de protección, a pesar de que ni la ley que se ha encargado de su desarrollo ${ }^{1}$ ni el Tribunal Constitucional se hayan encargado de definirlo explícitamente.

El concepto de intimidad se basa en una concepción subjetiva, habiéndose abandonado la idea material que estuvo vigente en otras épocas. Su protección y defensa dependen en gran medida de las concepciones sociales imperantes en cada momento, teniendo en cuenta que es ese espacio que la persona trata de proteger frente las miradas ajenas, es decir, que quiere reservarse para sí misma, y siempre como garantía para mantener el orden social con el objeto de lograr una convivencia social pacífica y ordenada ${ }^{2}$.

Consecuencia de esta nueva concepción, es la influencia ejercida por la teoría de los círculos concéntricos del alemán Heinrich Hubmann. Se ha encargado de distinguir tres esferas en la intimidad de las personas: privatsphäre (es una esfera privada que protege la intimidad personal y familiar que se desea mante-

1 Ley Orgánica 1/1982, de 5 de mayo, de Protección Civil del Derecho al Honor, a la Intimidad Personal y Familiar y a la Propia Imagen.

Se trata de una ley escasa e insuficiente, en la que se dejan abiertas grandes incógnitas, siendo la más notable el hecho de que no se defina en primer lugar de una forma clara y precisa el contorno de los derechos que está regulando, hecho que produce una cierta inseguridad jurídica. Además, no delimita la frontera entre los tres derechos autónomos que está protegiendo, y es que, aunque esta tarea ha sido llevada a cabo por la jurisprudencia, hubiera sido necesario apreciarla en el conjunto de artículos del texto.

2 Para Rebollo Delgado el derecho a la intimidad "no puede en ningún caso ser cerrado, es debida a esta conclusión a que la idea que se tiene de intimidad varía de una persona a otra, de un grupo a otro, de una sociedad a otra. Son elementos determinantes en su configuración la edad, la cultura, la educación, la comunidad en la que nos integramos. De entre ellos, el elemento de mayor influencia en la determinación del contenido esencial del derecho a la intimidad es la conformación social que de él realiza una sociedad en un momento determinado (...). Con lo manifestado, cabe entender al derecho a la intimidad como la protección de la autorrealización del individuo", Rebollo Delgado (2005), pp. 93-94.

También hay que destacar la idea que aporta en este campo Noreña Salto, quien afirma que la intimidad es “... un derecho de exclusión de terceros: con la intimidad se concede a un individuo o un pequeño grupo de personas - la familia - la facultad de impedir que otras personas ajenas puedan acceder al conocimiento -y, con mayor motivo, a la divulgación- de determinados hechos que afectan a aquél o aquéllos, y respecto de los que existe conformidad en que han de calificarse de íntimos o personales", Noreña SaLto (2002), p. 56. 
ner alejada del resto de la sociedad; está configurada por informaciones que el individuo sólo desea que sean conocidas por una determinada persona o grupo de personas), vertravensphäre (es una esfera más cerrada que la anterior, en la que el individuo solo revela cierta información a la gente de su total confianza, a su círculo más íntimo) y geheimsphäre (es la esfera del secreto, la que recoge esa parte de la vida que cada persona mantiene totalmente alejada de todos los demás). En palabras de Manuel Medina Guerrero “... la clasificación de una determinada información personal en uno u otro nivel resulta determinante para resolver la controversia: cuanto más se acerque el dato revelado al núcleo duro de lo materialmente íntimo, mayor relevancia deberá exigirse a la información para considerar que su difusión es constitucionalmente legítima (...)”3.

En definitiva, esta teoría, a pesar de no ser la más contemporánea, es la más ajustada a la delimitación actual que tiene el derecho a la intimidad en Europa, debido a que le ofrece un amplio margen de libertad para poder ir incorporando ciertos elementos que en el pasado no se consideraban susceptibles de protección y reconocimiento dentro de los límites de configuración de este derecho fundamental.

Una vez delimitado el contenido clásico del derecho constitucional a la intimidad dentro del ordenamiento jurídico español, esta investigación parte de la hipótesis de analizar las modificaciones que ha experimentado su contenido como consecuencia de la influencia que ejerce el Derecho europeo en el conjunto de los países del Viejo Continente.

Este Derecho internacional de carácter regional ha alterado el contenido esencial del derecho a la intimidad dentro del ordenamiento jurídico español, constituyendo este el principal objeto de estudio a desarrollar. Dibujar un boceto de los sistemas de derechos fundamentales europeos que están modificando el contenido de este grupo de derechos súper protegidos en el derecho interno de los Estados, para a continuación estudiar cuáles han sido las modificaciones que ha sufrido el derecho a la intimidad en España como consecuencia de la influencia ejercida tanto por el Consejo de Europa como por la Unión Europea. Todo con el objetivo de concluir sobre el estado actual de la cuestión a partir de esta nueva realidad jurídica del constitucionalismo multinivel.

3 Medina Guerrero (2005), pp. 13 y ss. 


\section{LA INFLUENCIA EUROPEA EN EL ÁMBITO DE LOS DERECHOS FUNDAMENTALES}

El reconocimiento y la defensa de los derechos fundamentales es el estandarte de cualquier sistema democrático estable. A lo largo de los años, este grupo de derechos se ha convertido en una auténtica seña de identidad, y no solo de los Estados, sino también de las Organizaciones Internacionales ${ }^{4}$, especialmente de dos de las que forma parte España: el Consejo de Europa y la Unión Europea.

Es importante aclarar una cuestión: todos los países de la UE forman parte del Consejo de Europa, pero no todos los países del Consejo de Europa forman parte de la UE, ya que para ingresar en esta última, es imprescindible cumplir con los requisitos exigidos en la primera, especialmente en el plano económico, político y social.

Los orígenes del Consejo de Europa se debieron, en gran parte, a que después de la IIGM5 se quiso evitar a toda costa que volviese a estallar un conflicto de unas consecuencias humanas, económicas, políticas y sociales tan catastróficas, momento en el que germinó la idea de que era necesario crear una Organización Internacional que evitase futuros problemas bélicos ${ }^{6}$.

Su creación ha supuesto un gran avance en el ámbito de los derechos fundamentales, ya que además de tener un texto dedicado íntegramente a esta materia, el Convenio Europeo de Derechos Humanos (a partir de ahora CEDH), aprobado en Roma el 4 de noviembre de 1950, se ha pretendido fomentar una unión más estrecha entre los diferentes países miembros para crear un mapa más homogéneo respecto del reconocimiento y protección de este grupo de derechos.

$\mathrm{El} \mathrm{CEDH}$ es el garante de los derechos fundamentales en el seno del Consejo de Europa, garantizando todos los derechos recogidos en su texto a todas las

\footnotetext{
4 Díez de Velasco (2010), p. 43: “... son unas asociaciones voluntarias de Estados establecidas por acuerdo internacional, dotadas de órganos permanentes, propios e independientes, encargados de gestionar unos intereses colectivos y capaces de expresar una voluntad jurídicamente distinta de la de sus miembros (...). La noción propuesta menciona los cuatro elementos que, a nuestro entender, permiten diferenciar las Organizaciones Internacionales de otras entidades afines. Estos caracteres esenciales (...) son: una composición esencialmente interestatal, una base jurídica generalmente convencional, una estructura orgánica permanente e independiente y, finalmente, una autonomía jurídica”.

5 Segunda Guerra Mundial.

6 Para González Pascual "los objetivos que debía cumplir el Consejo de Europa se enmarcaban en el momento histórico en el que fue ideado. Así, debía ayudar a evitar una nueva guerra en la Europa occidental, configurar un sistema de valores que contrastara con el régimen soviético, reforzar un sentimiento de identidad común y detectar con antelación posibles derivas autoritarias en Europa. El CEDH era el instrumento principal para cumplir dichos fines", González Pascual (2013), pp. 110-111.
} 
personas que se encuentren o que sean ciudadanos de cualquiera de los Estados firmantes", tal como manifiesta en el artículo 1 que reza: "Las Altas Partes Contratantes reconocen a toda persona dependiente de su jurisdicción los derechos y libertades definidos en el título I del presente Convenio".

Por su parte, la Unión Europea es considerada como la única institución que actúa tanto en el sistema interno como en el sistema mundial. Es una Organización Internacional de carácter regional que actualmente está formada por 28 países 8 y que en los próximos años posiblemente se verá ampliada ${ }^{9}$, ya que hay varios países candidatos (Turquía, Macedonia, Montenegro, Serbia, Albania y Bosnia). Tal como ha definido Concepción Escobar Hernández “la Unión Europea puede ser entendida como una realidad jurídico-política creada por los Estados miembros para ejecutar en su seno el proceso de integración europea, a través de una pluralidad de mecanismos y métodos de actuación que están sometidos a unos mismos principios y objetivos, y que utilizan una misma estructura institucional básicamente unificada" 10 .

A pesar de que sus inicios se reducen estrictamente al plano económico, pronto empezó a ampliar sus horizontes, forjando una idea hasta entonces inimaginable en el ámbito internacional: el establecimiento de unas directrices comunes en materia económica, política y social, para lo que se crearon una serie de instituciones que fomentasen la colaboración y la cooperación entre los distintos países.

En los primeros años de esta organización, los derechos fundamentales no constituían uno de sus objetivos prioritarios, a diferencia del Consejo de Europa. Los tratados fundacionales de la Comunidad Europea no incluyeron ningún catálogo de derechos fundamentales.

\footnotetext{
7 Carrillo Salcedo afirma que "este artículo es de excepcional relevancia en cuanto al alcance del Convenio, porque pone de manifiesto que este no se limita a proteger a europeos, nacionales de los Estados parte miembros del Consejo de Europa, sino que tiene un alcance mucho más amplio: en efecto, la dimensión del Convenio Europeo de Derechos Humanos es universal(...)”, Carrillo Salcedo (2003), p. 21.

8 Alemania, Austria, Bélgica, Bulgaria, Chipre, Croacia, Dinamarca, Eslovaquia, Eslovenia, España, Estonia, Finlandia, Francia, Grecia, Hungría, Irlanda, Italia, Letonia, Lituania, Luxemburgo, Malta, Holanda, Polonia, Portugal, Reino Unido, República Checa, Rumanía y Suecia.

9 Ojinaga Ruiz (2015), p. 24: “Durante más de seis décadas, el proceso de integración europea se ha visto desarrollado progresivamente sin necesidad de un modelo de referencia previamente establecido. La evolución que ha experimentado la Unión Europea puede resumirse, esencialmente, en los conceptos de ampliación y profundización. De hecho, y aunque con ritmos distintos, cada ampliación suele coincidir con una fase de profundización mediante el perfeccionamiento de la estructura institucional, la atribución de nuevas competencias a la Unión y el desarrollo de los diferentes aspectos de la construcción europea”.
}

10 Escobar Hernández (2015), pp. 33-34. 
Un punto de inflexión en su desarrollo se produjo con la promulgación del Tratado de Lisboa, el 13 de diciembre de 2007, tras el fracaso de la Constitución Europea de 2004. Este hito en la historia de la Unión Europea ha provocado que vuelva a funcionar mediante Tratados, en vez de establecer un marco constitucional estable y unitario para el conjunto de los Estados miembros.

En palabras de Mellado Prado “... con el Tratado de Lisboa, desaparecen la forma y los símbolos de la Constitución, manteniéndose el esquema tradicional de los Tratados. Y aunque se incorpora el 90\% del contenido de la antigua Constitución, se ha añadido una considerable complejidad, hasta el punto de que el Primer Ministro luxemburgués lo calificó de 'Tratado espeleológico', prácticamente ilegible para los ciudadanos. En definitiva, el Tratado de Lisboa supone, por una parte, una vuelta a la forma tradicional de reformar los Tratados 'a puerta cerrada'; y por otra -consecuencia de la anterior- la construcción de una Europa 'a la medida de los gobiernos' ya que se ha hecho desde los gobiernos y para los gobiernos, con el riesgo gravísimo de que 'toda reforma será una ocasión para el chantaje"'11.

Hasta la entrada en vigor del Tratado de Lisboa la Carta de Derechos Fundamentales de la Unión Europea (a partir de ahora CDFUE), firmada en la ciudad francesa de Niza el 7 de diciembre de 2000, no adquirió valor jurídico vinculante. Debido a esto, durante casi una década se recurrió al CEDH en materia de derechos fundamentales en ausencia de texto propio.

Esto no significa que durante los años precedentes la UE no haya estado preocupada por los derechos fundamentales, ya que el propio Tribunal de Luxemburgo es una de las instituciones comunitarias que más ha contribuido a garantizar su respeto. La importancia de su protección es tal que es una obligación que tienen que cumplir los países que deseen formar parte de esta Organización Internacional, condición que era ya exigida en los años 50 para el ingreso en las antiguas Comunidades Europeas. Mangas Martín afirma que "cuando se presentaron los primeros casos ante el Tribunal comunitario, sus primeras decisiones fueron titubeantes o tímidas sobre su competencia para conocer sobre la violación de derechos fundamentales, por cuanto se dudaba si era una esfera trasferida al Derecho Comunitario y amparada por él. Pero no tardó mucho el Tribunal de Justicia en tejer una doctrina jurisprudencial en torno a la protección de los derechos

11 Mellado Prado (2009), p. 32. 
fundamentales, convencido de la necesidad de fortalecer la unidad y primacía del Derecho Comunitario"12.

\subsection{Convivencia de dos sistemas de protección de los derechos fundamentales en el ámbito del Viejo Continente}

Dibujado este mapa de organizaciones internacionales que operan en Europa, se deduce que actualmente conviven dos sistemas de derechos fundamentales que se integran en los Estados miembros del Consejo de Europa y la Unión Europea, situación que está ocasionando algunos conflictos en la práctica, especialmente cuando se tiene que producir un diálogo entre los diferentes sistemas de protección.

Estos dos sistemas son el del CEDH del Consejo de Europa con su órgano judicial, el Tribunal Europeo de Derechos Humanos (a partir de ahora TEDH) con sede en Estrasburgo; y la CDFUE con su Tribunal de Justicia de la Unión Europea (a partir de ahora TJUE), también conocido como Tribunal de Luxemburgo por ser esta la ciudad donde está ubicada su sede.

En este punto se pronosticaron inevitables colisiones entre los criterios interpretativos de uno y otro tribunal con la consecuencia de que la tutela judicial de los derechos de los ciudadanos se convertiría, para quien pudiera permitírselo, en un peregrinaje de Corte en Corte, sin horizontes claros.

Y es que, a raíz de la adhesión de la Unión Europea al Convenio de Roma, prevista en el artículo 6 del Tratado de la Unión ${ }^{13}$, están rigiendo en el espacio jurídico europeo tres catálogos de derechos (el del CEDH, el de la CDFUE y el que hay en cada uno de los ordenamientos jurídicos internos), asistido además cada uno por su respectivo intérprete.

12 Mangas Martín (2008), p. 33.

13 Art. 6 TUE: "1. La Unión reconoce los derechos, libertades y principios enunciados en la Carta de los Derechos Fundamentales de la Unión Europea de 7 de diciembre de 2000, tal como fue adaptada el 12 de diciembre de 2007 en Estrasburgo, la cual tendrá el mismo valor jurídico que los Tratados. Las disposiciones de la Carta no ampliarán en modo alguno las competencias de la Unión tal como se definen en los Tratados. Los derechos, libertades y principios enunciados en la Carta se interpretarán con arreglo a las disposiciones generales del título VII de la Carta por las que se rige su interpretación y aplicación y teniendo debidamente en cuenta las explicaciones a que se hace referencia en la Carta, que indican las fuentes de dichas disposiciones. 2. La Unión se adherirá al Convenio Europeo para la Protección de los Derechos Humanos y de las Libertades Fundamentales. Esta adhesión no modificará las competencias de la Unión que se definen en los Tratados. 3. Los derechos fundamentales que garantiza el Convenio Europeo para la Protección de los Derechos Humanos y de las Libertades Fundamentales y los que son fruto de las tradiciones constitucionales comunes a los Estados miembros formarán parte del Derecho de la Unión como principios generales”. 
En este sentido, respecto a la adhesión de la Unión Europea al Convenio de Roma se ha producido un giro que probablemente va a perjudicar la protección de los derechos fundamentales en el ámbito del Viejo Continente, ya que en un dictamen vinculante del Tribunal de Luxemburgo del 18 de diciembre de 2014 de forma definitiva se ha rechazado la adhesión de la UE al CEDH, bajo el argumento principal de los presuntos riesgos que el control del Tribunal de Estrasburgo entraña para la salvaguardia de las características esenciales tanto de la Unión como de su Derecho propio ${ }^{14}$.

Por su parte, el TJUE es el encargado de velar por el cumplimiento de los derechos por parte de todos los Estados que conforman el ordenamiento jurídico comunitario, así como de estipular las correspondientes consecuencias jurídicas en caso contrario. Su principal misión consiste en interpretar el Derecho de la UE para garantizar que se aplique de la misma forma en todos los países miembros ${ }^{15}$. Además tiene competencia en los supuestos que están previstos en el Tratado de Lisboa, no siendo necesario el requisito de que el Estado la acepte expresamente, por lo que su jurisdicción es obligatoria, y sus decisiones se imponen a todos los países de la UE, así como a las instituciones y a los particulares.

Para Marcos Martín "el Tribunal de Justicia de la Unión Europea (...) es el eje central de protección jurisdiccional del Derecho de la Unión Europea. Se erige, así, en un auténtico poder judicial ya que, para el ejercicio de esa labor, los Tratados le han otorgado un conjunto de competencias que van desde la vigilancia del respeto a la legalidad por parte de las Instituciones hasta el control del respeto de este ordenamiento por parte de los Estados (...). Es el Tribunal de Justicia de la Unión Europea el que garantiza, en última instancia, la unidad

14 García VÁzQuez (2015), p. 266: "La particular naturaleza jurídica y política de la Unión Europea ha hecho necesarias largas negociaciones entre la Unión y el Consejo de Europa. El proyecto de acuerdo, alcanzado a mediados de 2013, se sometió a dictamen vinculante del Tribunal de Justicia de la UE que emitió su fallo el 18 de diciembre de 2014. Pues bien, sorprendentemente y a pesar de la opinión favorable de todos los actores que participaron en el proceso, el Tribunal de Justicia de la Unión Europea detectó varias razones para oponerse a él, casi todas vinculadas a los presuntos riesgos que el control del Tribunal de Estrasburgo entraña para la salvaguardia de las características esenciales de la Unión y de su Derecho propio".

15 MARICA (2013), p. 115: "El Tratado de Lisboa confirma que el Tribunal de Justicia de la Unión Europea garantizará el respeto del Derecho de la Unión en la interpretación y aplicación de los Tratados y además de este objetivo o función clave, el Tribunal de Justicia tiene encomendado el control de la legalidad de los actos legislativos-Reglamentos y Directivas, que emanen del Consejo, Comisión y del Banco Central Europeo y también los actos del Parlamento y del Consejo Europeo con fuerza vinculante para terceros". 
en la interpretación y aplicación del Derecho de la Unión y, por tanto, a él le corresponde garantizar la unidad jurisprudencial" 16 .

La labor del Tribunal de Luxemburgo ha sido esencial a la hora de aplicar de manera uniforme y eficiente el Derecho originario y derivado en todos los países de la Unión Europea. Desde el punto de vista constitucional se han tejido una serie de valores y principios a partir de los cuales todas las autoridades europeas han actuado conforme a los requisitos del imperio del Derecho.

También es destacable el valor de la jurisprudencia emanada del TEDH, cuyas sentencias son directamente obligatorias para los Estados miembros del Consejo de Europa ${ }^{17}$, aunque esto no significa que sean ejecutivas, sino que son declarativas, teniendo posteriormente los países cierta libertad de actuación para su ulterior ejecución.

El diálogo entre estos dos tribunales europeos ${ }^{18}$ se vio muy claro a partir del 2000, cuando ambos sistemas estuvieron plenamente formados. Este hecho demostró la importancia de los órganos judiciales europeos en el derecho interno de los Estados miembros, ya que hasta hacía pocas décadas esta situación era totalmente impensable, porque los jueces solo estaban sometidos a sus respectivos ordenamientos estatales.

Tal como afirma Ripol Carulla “... las influencias recíprocas que se producen entre la jurisprudencia de los tribunales superiores de los Estados y de los tribunales internacionales, entre la jurisprudencia de los tribunales nacionales entre sí y, por último, entre la jurisprudencia de los propios tribunales internacionales, se puede ejemplificar en la creciente influencia entre los dos tribunales europeos: el Tribunal de Justicia y el Tribunal Europeo de Derechos Humanos, cuyas decisiones han adquirido un eco enorme en la configuración jurídica de los derechos fundamentales en el marco de la jurisprudencia comunitaria" 19 .

16 Marcos Martín (2015), p. 158.

17 Art. 46 CEDH: "Fuerza obligatoria y ejecución de las sentencias. 1. Las Altas Partes Contratantes se comprometen a acatar las sentencias definitivas del Tribunal en los litigios en que sean parte. 2. La sentencia definitiva del Tribunal será transmitida al Comité de Ministros, que velará por su ejecución”.

18 López Guerra (2013), p. 141: “El concepto de 'diálogo entre tribunales'. Ciertamente, se trata de una noción que se ha empleado con significados muy distintos, que van desde la mera cita por un tribunal de resoluciones de otro hasta la presencia de una efectiva interacción entre tribunales, es decir, de un proceso de influencias recíprocas en el sentido de que un tribunal reacciona conscientemente ante la apreciación que de su conducta haya realizado otro tribunal".

19 Ripol Carulla (2007), pp. 64-65. 


\subsection{La influencia europea en el ordenamiento jurídico español}

El derecho internacional, dentro del cual se enmarca el derecho europeo, constituye un ordenamiento jurídico propio y autónomo que debe ser cumplido en España, tal como establece el artículo 96.1 CE que dice: "Los tratados internacionales válidamente celebrados, una vez publicados en España, formarán parte del ordenamiento interno. Sus disposiciones solo podrán ser derogadas, modificadas o suspendidas en la forma prevista en los propios tratados o de acuerdo con las normas generales del Derecho internacional". Por su parte, el art. 10.2 CE ${ }^{20}$ dice que "las normas relativas a los derechos fundamentales y a las libertades que la Constitución reconoce se interpretarán de conformidad con la Declaración Universal de Derechos Humanos y los tratados y acuerdos internacionales sobre las mismas materias ratificados por España”.

Esta integración del derecho europeo en el ordenamiento jurídico español está prevista en el propio texto constitucional, concretamente en el art. $93 \mathrm{CE}^{21}$, mecanismo previsto para transferir competencias a las instituciones europeas.

El propio Tribunal Constitucional ha ratificado esta operación en algunos de sus pronunciamientos, como por ejemplo en la STC 1/2004, de 13 de febrero, en cuyo Fundamento Jurídico 2 explica que “... el art. 93 CE es sin duda soporte constitucional básico de la integración de otros ordenamientos con el nuestro, a través de la cesión del ejercicio de competencias derivadas de la Constitución, ordenamientos llamados a coexistir con el ordenamiento interno, en tanto que ordenamientos autónomos por su origen. En términos metafóricos podría decirse que el art. $93 \mathrm{CE}$ opera como bisagra mediante la cual la Constitución misma da entrada en nuestro sistema constitucional a otros ordenamientos jurídicos a través de la cesión del ejercicio de competencias. De este modo se confiere al art.

\footnotetext{
20 Ruiz Miguel (1994), pp. 17-18: "En efecto, el artículo 10.2 CE declara que la interpretación de los derechos fundamentales reconocidos en la Constitución diverge de las reglas ordinarias de interpretación constitucional, siendo aquí el criterio primordial el de la interpretación, no solo de la Constitución misma, sino también de la Declaración Universal de derechos humanos y demás tratados suscritos por España sobre tal materia. El artículo 10.2 CE constituye una cláusula singular en el panorama del Derecho Constitucional comparado. Este artículo establece un régimen interpretativo especial para los derechos fundamentales que se separa de las reglas que rigen la interpretación del resto de la Constitución”.

21 Art. 93 CE: "Mediante ley orgánica se podrá autorizar la celebración de tratados por los que se atribuya a una organización o institución internacional el ejercicio de competencias derivadas de la Constitución. Corresponde a las Cortes Generales o al Gobierno, según los casos, la garantía del cumplimiento de estos tratados y de las resoluciones emanadas de los organismos internacionales o supranacionales titulares de la cesión”.
} 
$93 \mathrm{CE}$ una dimensión sustantiva o material que no cabe ignorar. Producida la integración debe destacarse que la Constitución no es ya el marco de validez de las normas comunitarias, sino el propio Tratado cuya celebración instrumenta la operación soberana de cesión del ejercicio de competencias derivadas de aquélla, si bien la Constitución exige que el Ordenamiento aceptado como consecuencia de la cesión sea compatible con sus principios y valores básicos (...)”.

Pero esta transferencia de competencias no es ilimitada, por lo que el máximo garante de la Carta Magna se ha encargado de recoger cuáles son los límites que no se pueden traspasar en este supuesto de cesión de competencias de España hacia Europa: respeto a la soberanía del Estado, respeto a las estructurales constitucionales españolas y respeto a los valores y a los principios fundamentales consagrados en la $\mathrm{CE}^{22}$.

La interpretación de estos dos preceptos constitucionales se enmarca en el camino de que tanto el CEDH como la CDFUE deben ser respetados por los tribunales españoles, en la misma medida que ocurre con la CE y con el conjunto legislativo que integra el ordenamiento jurídico.

Esto no significa que estos dos textos jurídicos que se encargan del reconocimiento y la protección de los derechos fundamentales en el marco europeo estén por encima de la $\mathrm{CE}$, sino que han atravesado la clásica pirámide de Kelsen de la estructura de las fuentes jurídicas españolas.

El Tribunal Constitucional español ha tenido que concretar el contenido de determinados derechos fundamentales para ajustarlos a la nueva realidad jurídica nacional, que es que actualmente España tiene un ordenamiento jurídico multinivel como consecuencia de su pertenencia al Consejo de Europa y a la Unión Europea.

El ordenamiento jurídico español se ha tenido que adaptar en varias ocasiones a las directrices marcadas por Europa en el ámbito de los derechos fundamentales. En palabras de González Pascual "el derecho constitucional europeo y el nacional conforman un sistema desde una perspectiva material, funcional e institucional. Dicho sistema ha sido adjetivado como unión de constituciones, constitucio-

22 STC 1/2004, de 13 de febrero, FJ2: “... la cesión constitucional que el art. 93 CE posibilita tiene a su vez límites materiales que se imponen a la propia cesión. Esos límites materiales, no recogidos expresamente en el precepto constitucional, pero que implícitamente se derivan de la Constitución y del sentido esencial del propio precepto, se traducen en el respeto de la soberanía del Estado, de nuestras estructuras constitucionales básicas y del sistema valores y principios fundamentales consagrados en nuestra Constitución, en el que los derechos fundamentales adquieren sustantividad propia (art. 10.1 CE), límites que, como veremos después, se respetan escrupulosamente en el Tratado objeto de nuestro análisis (...)”. 
nalismo multinivel, orden constitucional europeo, sistema de entrelazamiento constitucional, comunidad constitucional o constitución en red. En consecuencia, una dimensión fundamental de la efectividad del TEDH es su capacidad para convertirse en pilar de dicho Derecho Constitucional Europeo"23.

En definitiva, todo este nuevo conjunto legislativo, nacido del proceso de globalización que se ha experimentado principalmente en los últimos 50 años, ha provocado la creación europea de un nuevo constitucionalismo multinivel en el que las Constituciones de cada uno de los Estados miembros, el Derecho de la UE y al CEDH forman un ordenamiento único ${ }^{24}$.

\section{El CASO CONCRETO DEL DERECHO A LA INTIMIDAD EN ESPAÑA}

El derecho a la intimidad en España se ha visto influido directamente por el constitucionalismo multinivel en el que se encuentra inmerso el contenido protegible de los derechos fundamentales, cuya consecuencia directa es la gran complejidad de la articulación, así como de la interpretación de los ordenamientos jurídicos actuales, debido a la coexistencia de un número muy elevado de normas de distinta jerarquía, naturaleza, ámbito de aplicación, así como de origen. Tal como afirma Gómez Sánchez “... cuando se estudian derechos y libertades concretos, se adopta el enfoque multinivel de forma que se ofrece un estudio integrado de la materia en los diferentes niveles normativos que la afectan con referencias a las normas de producción externa (...) e interna (...) que estén involucrados en cada caso" 25 .

A continuación se va a llevar a cabo un análisis en el que se va a verificar cómo los dos sistemas de derechos fundamentales que operan en el ámbito del Viejo Continente han producido modificaciones en el derecho fundamental a la intimidad dentro del ordenamiento jurídico español.

23 González Pascual (2013), pp. 110-111.

24 Tal como afirma García Vázquez "Todos los argumentos a favor de la adhesión de la UE al $\mathrm{CEDH}$ se resumen en una idea fundamental que se reconduce a reforzar la imagen democrática de Europa hacia dentro en el sentido de que todos los ciudadanos europeos nos encontremos amparados en un elenco reforzado de derechos, y hacia fuera, enviando el mensaje de que Europa está fuertemente blindada en materia de derechos fundamentales, tratando de ser un ejemplo a seguir por el resto de países aún no democráticos, o con democracias endebles", GARCía VÁzQUEZ (2015), p. 266.

25 Gómez SÁnchez (2008), p. 58. 


\subsection{El derecho a la intimidad en el seno del Consejo de Europa}

Ya en los años 50 el Consejo de Europa fue plenamente consciente de la importancia del reconocimiento y la protección de los derechos de la personalidad, entre los que se encuentra el derecho a la intimidad que aparece recogido en el artículo 8 del CEDH que reza: "1. Toda persona tiene derecho al respeto de su vida privada y familiar, de su domicilio y de su correspondencia. 2. No podrá haber injerencia de la autoridad pública en el ejercicio de este derecho, sino en tanto en cuanto esta injerencia esté prevista por la ley y constituya una medida que, en una sociedad democrática, sea necesaria para la seguridad nacional, la seguridad pública, el bienestar económico del país, la defensa del orden y la prevención del delito, la protección de la salud o de la moral, o la protección de los derechos y las libertades de los demás".

En este artículo ha desaparecido la unión que existía en materia internacional entre los conceptos vida privada y honra, tal como explica Rebollo Delgado: "Dos comentarios nos devienen como necesarios respecto del citado artículo del Convenio. El primero, es que ha desaparecido la unión de la vida privada y la honra y fama en un mismo artículo. Es más, el Convenio no recoge de forma explícita estos últimos derechos. Con ello se aparta del reconocimiento internacional. El segundo aspecto significativo es que el artículo 8.2 recoge de forma profusa las excepciones a la vigencia del derecho, que se concretan en las siguientes: que la injerencia "esté prevista por ley, y constituya una medida que, en una sociedad democrática, sea necesaria para la seguridad nacional, la seguridad pública, el bienestar económico del país, la defensa del orden y la prevención del delito, la protección de la salud o de la moral, o la protección de los derechos y libertades de los demás". Como puede comprobarse, muchas son las excepciones y con ser ello grave, aún lo es más la indefinición jurídica de los conceptos utilizados como límite" 26 .

El Convenio entiende, de forma acertada, que la vida privada y la honra son dos derechos diferenciados, ya que el honor y la intimidad, a pesar de ser dos derechos de la personalidad, protegen aspectos diferenciados de la persona humana.

Aunque, desafortunadamente se ha olvidado de reconocer la protección respecto de la honra de las personas, así como de la propia imagen, por lo que cuando un ciudadano, que se encuentre bajo la protección de este texto jurídico, quiera alegar la vulneración de alguno de estos dos derechos tiene que invocar el

26 Rebollo Delgado (2005), pp. 226-227. 
artículo 8 del CEDH, que no se encarga exactamente de la protección de los mismos, sino de la vida privada. Esta situación puede producir que en determinadas ocasiones brote una confusión respecto de estos tres derechos de la personalidad, o sea, entre el honor, la intimidad y la propia imagen.

Respecto a la diferenciación entre intimidad y vida privada, el TEDH ha dado cuenta de ello, aunque no define explícitamente ninguno de los dos conceptos. Sería positivo que el Tribunal de Estrasburgo explicitara el contenido de cada uno de ellos, debido a que los conceptos jurídicos indeterminados producen situaciones de inseguridad jurídica que se pueden evitar cuando existe una definición clara y precisa del contenido de los derechos que se está protegiendo.

Relativo a los límites del artículo $8 \mathrm{CEDH}$ existe una postura clara y bien definida sobre en qué casos se puede permitir su restricción, es decir, cuándo debe ceder frente a otro derecho fundamental con el que haya colisionado. Para que esto sea posible es necesario que la injerencia cumpla con tres requisitos: que esté prevista por la ley (existencia de una base legal en Derecho interno), que atienda a un interés legítimo y que sea necesaria para el correcto funcionamiento de una sociedad democrática (que sea útil, razonable o incluso indispensable) ${ }^{27}$.

Pero además del CEDH, la jurisprudencia dictada por el Tribunal de Estrasburgo ha influido en la configuración actual del derecho a la intimidad en España.

La sentencia más importante que existe en materia de intimidad es el Caso López Ostra c. España de 9 de diciembre de 1994, cuyos hechos fueron los siguientes: una señora murciana denuncia que se han instaurado cerca de su domicilio varias industrias de encurtidos que están violando su derecho a la intimidad personal y familiar, debido a las graves molestias que le están ocasionando dentro de su casa, con el consiguiente empeoramiento de su calidad de vida. La empresa, llamada SACURSA, se instala en terrenos del Ayuntamiento y además recibe subvenciones del Estado. Finalmente se consigue la paralización parcial de las actividades, pero según unos informes periciales se sabe que hay ciertas molestias que persisten y que pueden constituir un peligro para la salud de los vecinos.

La demandante alega vulneración del artículo $8 \mathrm{CEDH}$ por violación de su intimidad domiciliaria, implícita en el derecho a la intimidad que protege dicho precepto. El TEDH estima que sí se produjo transgresión del mismo, debido a todas las molestias que tuvo que soportar, y es que, tal como dice en el Fundamento de Derecho 51: “... ni qué decir tiene que los atentados graves al medioambiente

27 Ruiz Miguel (1994), p. 89: "Estos requisitos deben examinarse sucesivamente. Si no cumple uno solo de estos tres requisitos la injerencia violará el artículo 8". 
pueden afectar al bienestar de una persona y privarla del disfrute de su domicilio, perjudicando su vida privada y familiar, sin, por ello, poner en grave peligro la salud de la interesada".

En definitiva, se establece la obligación de adoptar medidas de prevención contra ataques graves al medioambiente que afecten al bienestar de las personas perjudicando el desarrollo de su vida privada y familiar. El Tribunal de Estrasburgo considera que este tipo de molestias deterioran la calidad de vida de los vecinos, desde el momento en que se impide a una persona el normal disfrute de su domicilio.

Esta STEDH es la encargada de incorporar al ordenamiento jurídico español la idea de que los contenidos medioambientales forman parte de la intimidad ${ }^{28}$, así como que las molestias en el domicilio suponen una vulneración del artículo 8 CEDH, ya que no hay nada más privado en la vida de las personas que su hogar.

Esta idea ha tenido posteriormente un importante desarrollo jurisprudencial, ya que a pesar de que la intimidad domiciliaria es un derecho fundamental con un contenido propio y autónomo en la gran mayoría de los textos constitucionales de los ordenamientos jurídicos civilistas, no se puede perder de vista su estrecha relación con el derecho a la intimidad. Muy acertadamente, el Tribunal de Estrasburgo ha incorporado este contenido al núcleo de garantía protegible por la intimidad, porque este es el espacio donde se alcanza la máxima expresión de este derecho fundamental.

Otra importante STEDH contra España relacionada con el artículo $8 \mathrm{CEDH}$, es el Caso Valenzuela Contreras c. España de 30 de julio de 1998. Los hechos se producen con motivo de unas escuchas telefónicas por parte del Juez de Instrucción núm. 31 de Madrid que las autorizó.

Por su parte, el TEDH considera que la "i. Interceptación de las conversaciones telefónicas constituye una injerencia de una autoridad pública en el derecho al respeto a la vida privada y a la correspondencia. Tal injerencia vulnera el artículo 8.2 salvo si "prevista por la ley", persigue uno o varios fines legítimos respecto al párrafo 2 y además es "necesaria, en una sociedad democrática” para alcanzarlos". ii. Las palabras "prevista por la ley" buscan, en primer lugar, que la medida indis-

28 Casino Rubio (2013), p. 428: "Esta Sentencia, aunque anunciada en otras anteriores resoluciones del TEDH, afirma no obstante de modo resuelto y por primera vez la conexión que a juicio del TEDH existe entre la vida privada y familiar y el medio ambiente y la obligación positiva del Estado de adoptar las correspondientes medidas a fin de asegurar el efectivo respeto a los derechos garantizados por el art. 8 del Convenio". 
criminada tenga una base en el derecho interno. Sin embargo, esta expresión no se limita a remitir al derecho interno, sino que concierne también a la calidad de la "ley"; exige que sea compatible con la preeminencia del derecho, implicando así que el derecho interno debe ofrecer una cierta protección contra atentados arbitrarios de los poderes públicos a los derechos garantizados en el párrafo 1 (...). iii. El peligro de arbitrariedad aparece con singular nitidez allí donde un poder de apreciación se ejerce en secreto. Cuando se trata de medidas de vigilancia o de la interpretación de comunicaciones por las autoridades públicas, la exigencia de previsibilidad implica que el derecho interno debe emplear términos suficientemente claros para indicar a todos de manera suficiente en qué circunstancias y bajo qué condiciones habilita a los poderes públicos a tomar tales medidas (...). iv. Como garantías mínimas, necesarias para evitar los abusos, que deben figurar en la ley, las Sentencias Kruslin y Huvig, mencionan: la definición de las categorías de personas susceptibles de ser sometidas a vigilancia telefónica judicial; la naturaleza de las infracciones a que puedan dar lugar; la fijación de un límite a la duración de la ejecución de la medida; las condiciones de establecimiento de los atestados que consignen las conversaciones interceptadas; las precauciones que se deben tomar para comunicar, intactas y completas, las grabaciones realizadas, con el fin de ser controladas eventualmente por el Juez y la defensa; las circunstancias en las que se puede o se debe realizar el borrado o la destrucción de dichas cintas, sobre todo tras un sobreseimiento o una absolución”.

O sea, con esta sentencia, se sigue ampliando el contenido protegible del derecho a la intimidad. Se protegen aspectos que en el caso español no se consideraban como propios del núcleo de garantía esencial de este derecho fundamental. Gracias a la labor de este Tribunal Internacional, el derecho a la intimidad dentro de las fronteras españolas amplía, de manera muy acertada, el contenido que es susceptible de reconocimiento y protección.

Y la STEDH española contemporánea más conocida respecto al derecho a la intimidad es el Caso Moreno Gómez c. España de 16 de noviembre de 2004, en la que la demandante, que vivía en una zona residencial de Valencia, denuncia al Ayuntamiento de la ciudad por vulneración de su intimidad domiciliaria, como consecuencia de que el Consistorio permitió la apertura de varios establecimientos nocturnos (bares, pubs y discotecas), perjudicando gravemente el descanso de los vecinos. Además, a pesar de que la policía autonómica informó a las autoridades correspondientes de que los locales superaban los niveles de decibelios permitidos e infringían los horarios de cierre, las autoridades competentes concedieron una licencia para la apertura de una nueva discoteca en el inmueble de la demandante. 
El TEDH vuelve a condenar a España por violación del artículo $8 \mathrm{CEDH}$, alegando que el individuo tiene derecho al respeto de su domicilio, no pudiéndose tolerar que a nadie se le pueda privar del disfrute de su intimidad domiciliaria, tal como explica en el Fundamento de Derecho 53: "El artículo 8 del Convenio protege el derecho del individuo al respeto de su vida privada y familiar, de su domicilio y su correspondencia. El domicilio es normalmente el lugar, el espacio físicamente determinado en donde se desarrolla la vida privada y familiar. El individuo tiene derecho al respeto de su domicilio, concebido no solo como el derecho a un simple espacio físico, sino también como el derecho a disfrutar en toda tranquilidad de dicho espacio. Las vulneraciones del derecho de respeto al domicilio no solamente son las de índole material o corporal, tales como la entrada en el domicilio de una persona no autorizada, sino también las agresiones inmateriales o incorpóreas, como ruidos, emisiones, olores u otras injerencias. $\mathrm{Si}$ las agresiones son graves pueden privar a una persona de su derecho al respeto del domicilio porque le impiden gozar del mismo".

Con esta Sentencia el Tribunal de Estrasburgo refuerza su jurisprudencia respecto a la protección del domicilio como parte de la intimidad privada y familiar, porque al fin y al cabo, el hogar es el espacio más íntimo de cada uno, donde realmente las personas pueden desarrollarse y ser libres, siendo precisamente en este ámbito donde este derecho juega su máximo potencial, por lo que si esa área se ve violada por injerencias externas, la intimidad de esos ciudadanos también se verá vulnerada.

\section{El derecho a la intimidad en el seno de la Unión Europea}

En el ámbito de la UE, el derecho a la intimidad en España también ha sufrido modificaciones como consecuencia del Derecho europeo. La intimidad viene recogida en el artículo 7 de la CDFUE en los siguientes términos: "Toda persona tiene derecho al respeto de su vida privada y familiar, de su domicilio y de sus comunicaciones".

Este artículo, a diferencia del artículo $8 \mathrm{CEDH}$, no recoge las limitaciones fundamentales que se deben tener en cuenta respecto al derecho a la intimidad, razón por la cual el TJUE tiene aceptado las que vienen explicitadas en el segundo párrafo del artículo $8 \mathrm{CEDH}$.

Asimismo, en el ámbito de la UE el derecho a la intimidad se entiende como un derecho diferenciado de la protección de datos personales. Este último derecho aparece recogido en un precepto diferenciado de la CDFUE, concretamente en el 
artículo 8, que dice: " 1 . Toda persona tiene derecho a la protección de los datos de carácter personal que la conciernan. 2. Estos datos se tratarán de modo leal, para fines concretos y sobre la base del consentimiento de la persona afectada o en virtud de otro fundamento legítimo previsto por la ley. Toda persona tiene derecho a acceder a los datos recogidos que la conciernan y a obtener su rectificación. 3. El respeto de estas normas estará sujeto al control de una autoridad independiente". Esta situación se debe, a que como consecuencia de los grandes avances tecnológicos que se han producido en las últimas décadas, la protección de los datos de las personas físicas es susceptible de una protección específica.

De hecho, en el ámbito del Derecho derivado no existe legislación específica que se encargue de regular exclusivamente la protección del derecho a la intimidad, pero sí se encuentra regulada la protección de datos personales, o ambos derechos de forma conjunta. En este ámbito es de vital importancia resaltar el Reglamento (UE) 2017/679 relativo a la protección de las personas físicas en lo que respecta al tratamiento de sus datos personales y a la libre circulación de estos datos y por él se deroga la Directiva 95/46/CE, conocida como el Reglamento general de protección de datos ${ }^{29}$.

29 Es aplicable a la protección de datos personales de las personas físicas identificadas o identificables (excluye a las personas jurídicas, así como a las personas físicas fallecidas), en el contexto de una actividad profesional o comercial, quedando excluidas de su ámbito de aplicación las actividades de curso personal o doméstico.

Esta nueva legislación en materia de protección de datos personales persigue el claro objetivo de homogeneizar esta cuestión en el conjunto de los Estados miembros, a pesar de que una parte importante de sus artículos deberán ser interpretados a nivel nacional, ya que el Reglamento deja abierta la posibilidad a los EEMM para que regulen internamente numerosas cuestiones, labor que en el caso español deberá desarrollar la Agencia Española de Protección de Datos.

Otro de los objetivos que persigue el Reglamento es dar respuesta a las nuevas necesidades surgidas como consecuencia de los avances tecnológicos, ya que tal como afirma en su Considerando 6 "la rápida evolución tecnológica y la globalización han planteado nuevos retos para la protección de los datos personales. La magnitud de la recogida y del intercambio de datos personales ha aumentado de manera significativa. La tecnología permite que tanto las empresas privadas como las autoridades públicas utilicen datos personales en una escala sin precedentes a la hora de realizar sus actividades. Las personas físicas difunden un volumen cada vez mayor de información personal a escala mundial. La tecnología ha transformado tanto la economía como la vida social, y ha de facilitar aún más la libre circulación de datos personales dentro de la Unión y la transferencia a terceros países y organizaciones internacionales, garantizando al mismo tiempo un elevado nivel de protección de los datos personales".

Se ha elaborado con el objetivo de abordar los nuevos retos tecnológicos aparecidos, o sea, para establecer un control más riguroso en el ámbito de Internet (redes sociales, smartphones, páginas de compra online, etc.), de forma que el usuario pueda decidir qué información personal quiere compartir a través de la Red. 
En este contexto es necesario destacar también la Directiva 58/2002/CE del Parlamento Europeo y del Consejo, de 12 de julio de 2002, que quiere garantizar la protección del derecho a la intimidad tal como se concibe en la CDFUE, para que las nuevas tecnologías no vulneren impunemente los derechos de la personalidad de los ciudadanos de la Unión.

Esta Directiva se encarga de regular el tratamiento de los datos personales y la protección de la intimidad en el sector de las comunicaciones electrónicas como consecuencia del desarrollo de la sociedad de la información.

Además de la legislación, la jurisprudencia europea también ha influido en la configuración actual del derecho a la intimidad en el ordenamiento jurídico español. El TJUE se ha pronunciado en varias ocasiones respecto a problemas relativos con el derecho a la intimidad, ya que desde la aprobación del Tratado de Lisboa son numerosas las situaciones en las que ha tenido que dirimir en conflictos entre derechos fundamentales y también sobre libertades públicas.

En el ámbito concreto del derecho objeto de estudio, finalmente el Tribunal de Luxemburgo no ha optado por desarrollar una definición explícita del concepto de intimidad. En palabras de Rebollo Delgado "el TJCE ha tenido en dos ocasiones la posibilidad de establecer su reconocimiento, pero ha optado por no emitir un concepto de intimidad personal. La primera ocasión es en el Caso Stauder. En él se solventa la legalidad o no de suministrar una lista nominativa de unos beneficiarios de asistencia social. Resumimos el fallo del Tribunal en los siguientes términos: 'la disposición litigiosa no establece ningún elemento susceptible de poner en entredicho los derechos fundamentales de la persona comprendidos en los principios generales del Derecho Comunitario cuyo respeto asegura el Tribunal'. El segundo asunto significativo en el que el TJCE elude pronunciarse al respecto del derecho a la intimidad personal lo encontramos en el Caso Watson y Belmann. El fondo del asunto lo constituye una norma italiana que obliga a

Dictado al amparo del derecho fundamental de la protección de datos, todavía no se pueden establecer unas conclusiones, ni siquiera provisionales, sobre su eficacia debido a que no entrará en vigor hasta mediados de 2018. A pesar de esto, debido a su sólida redacción, así como la claridad de los aspectos que se deben respetar en relación con este derecho fundamental, es probable que llegue a convertirse en un buen instrumento jurídico para la protección de los datos personales. Especialmente para que pueda dar respuesta a las nuevas necesidades sociales que han surgido como consecuencia de los continuos abusos a los que miles de ciudadanos se están viendo sometidos a través del mundo virtual que todavía no está correctamente regulado jurídicamente. Por lo tanto, es necesario que se siga elaborando legislación en este sentido que proteja los derechos fundamentales de los ciudadanos en el entorno de Internet, ya que es la mejor manera de controlar que las empresas virtuales respeten los derechos de los usuarios. 
los extranjeros a poner en conocimiento de las autoridades su presencia y a los italianos que los alojan, de informar de ello en veinticuatro horas. El abogado general del Tribunal considera que estaba en juego el derecho a la vida privada y el derecho a la igualdad (arts. 8 y 14 CEDH). Por su parte, la Comisión no aprecia la violación del derecho a la igualdad, pero sí entiende el caso, como posible lesión de la vida privada que ha de ser sancionada por el TJCE. Éste no entró en lo sustantivo del asunto, argumentando que la cuestión corresponde básicamente al ordenamiento interno del Estado y que no puede ser contemplada desde la perspectiva del derecho comunitario más que como una repercusión indirecta de la restricción a la libre circulación de personas" 30 .

El Caso Stauder ${ }^{31}$, al que alude este autor, es considerado la primera ocasión en la que el Tribunal de Justicia de las Comunidades Europeas (no pasó a denominarse TJUE hasta la firma del Tratado de Lisboa en 2007) se pronunció acerca de un tema relacionado con el derecho a la intimidad, más concretamente respecto a un asunto de protección de datos.

En esta ocasión, tal como afirma Ruiz Miguel, el tribunal "tuvo que decidir si el supeditar el suministro de mantequilla con precios reducidos al hecho de que se suministrara a los vendedores previamente el nombre de los beneficiarios vulneraba algún derecho fundamental. Aunque el recurrente no alegó expresamente el derecho a la protección de datos personales era este, sin embargo, el que se hallaba en juego en esa ocasión. El tribunal afirmó que la directiva admitía varias lecturas en las distintas versiones y que no imponía ni prohibía la identificación nominal de los beneficiarios de ese tipo de ayudas, concluyendo que así no había ningún elemento que permitiera 'cuestionar los derechos fundamentales de la persona subyacentes en los principios generales del Derecho comunitario, cuyo respeto garantiza el tribunal'. Como se ve, el Tribunal eludió claramente identificar un derecho a la vida privada o a la protección de datos personales como tales" 32 .

El TJCE consideró que no había ningún elemento en el supuesto planteado susceptible de poner en entredicho los derechos fundamentales de la persona comprendidos en los principios generales del Derecho comunitario cuyo respeto asegura el órgano judicial.

30 Rebollo Delgado (2005), pp. 227-228.

31 STJCE de 12 de noviembre de 1969, Erich Stauder v. Stadt Ulm-Sozialamt.

32 Ruiz Miguel (2003), p. 179. 
Por su parte, en el Caso Watson y Belmann, el TJCE eludió pronunciarse al respecto del derecho a la intimidad personal. En este supuesto la controversia surge por una norma italiana que obligaba a los extranjeros a poner en conocimiento de las autoridades su presencia.

La Comisión no consideró que se hubiera producido una violación del derecho a la intimidad, bajo el argumento de que en realidad se trataba de una cuestión de derecho interno y que no podía ser contemplada desde la perspectiva del derecho comunitario.

Otro de los asuntos más nombrados en materia de intimidad europea es el asunto Carpenter 33 , en el que el TJCE puso de relieve la necesidad de reconocer el derecho a la intimidad familiar ${ }^{34}$ como uno de los derechos fundamentales que la Unión Europea debe proteger para todos sus ciudadanos, sentando jurisprudencia al respecto al establecer, en la Apreciación No 8 de la Sentencia, que “... el legislador comunitario ha reconocido la importancia de proteger la vida familiar de los nacionales de los Estados miembros para eliminar los obstáculos al ejercicio de las libertades fundamentales garantizadas por el Tratado (...)”.

El Tribunal relaciona la vida familiar con el derecho a la intimidad personal, y el hecho de que para su limitación es necesario, al igual que con la vertiente principal del derecho, que exista una justificación y que la medida sea proporcionada al objetivo que se pretende alcanzar, tal como explica en el Apreciando No 9: "La decisión de expulsión de la Sra. Carpenter constituye una injerencia en el ejercicio por el Sr. Carpenter de su derecho al respeto de su vida familiar, en el sentido del artículo 8 del Convenio para la Protección de los Derechos Humanos y de las Libertades Fundamentales, firmado en Roma el 4 de noviembre de 1950 (en lo sucesivo, 'Convenio'), que forma parte de los derechos fundamentales que, conforme a reiterada jurisprudencia del Tribunal de Justicia, reafirmada, además, en el preámbulo del Acta Única Europea y en el artículo 6 UE, apartado 2, están protegidos por el ordenamiento jurídico comunitario. Aunque el Convenio no

\footnotetext{
33 STJCE de 11 de julio de 2002, Mary Carpenter c. Secretary of State for the Home Department.

34 Otaegui Aizpúrua (2014), p. 151: "Pero una de las cuestiones más relevantes de esta Sentencia es, que en la misma el Tribunal reconoce el derecho fundamental a la vida familiar como parte de los derechos fundamentales de la Unión Europea. Así, el párrafo 41 establecía que “... la decisión de expulsión de la Sr. Carpenter de su derecho al respeto de su vida familiar, en el sentido del artículo 8 del Convenio para la Protección de los Derechos Humanos y de las Libertades Fundamentales, firmado en Roma el 4 de noviembre de 1950 (...), que forma parte de los derechos fundamentales que, conforme a reiterada jurisprudencia del Tribunal de Justicia, reafirmada, además, en el preámbulo del Acta Única Europea y en el artículo 6 UE, apartado 2, están protegidos por el ordenamiento jurídico comunitario"”.
} 
garantiza como tal ningún derecho a favor de un extranjero a entrar o residir en el territorio de un país determinado, excluir a una persona de un país en el que viven sus parientes próximos puede constituir una injerencia en el derecho al respeto de la vida familiar protegido por el artículo 8, apartado 1, del Convenio. Tal injerencia infringe el Convenio si no cumple los requisitos del apartado 2 del mismo artículo, a saber, que esté 'prevista por la ley' y motivada por una o más finalidades legítimas con arreglo a dicho apartado, y que, 'en una sociedad democrática' sea necesaria, es decir, que esté justificada por una necesidad social imperiosa y sea, en especial, proporcionada a la finalidad legítima perseguida”.

Y la última STJUE en la que se ha pronunciado el Tribunal de Luxembugo en relación con el derecho a la intimidad, es la del 13 de mayo de 2014, C-131/12, conocida como Caso Google. En este asunto, el señor Costeja demandó al periódico La Vanguardia y a Google Spain y Google Inc., porque al introducir su nombre en el buscador éste remitía a una noticia publicada en este diario sobre un anuncio de una subasta de inmuebles relacionada con un embargo por deudas con la Seguridad Social. A pesar de que se trata de un tema relacionado con el derecho al olvido, debido la relación directa que éste tiene con el derecho a la intimidad, así como por la gran repercusión que ha tenido en el mundo jurídico, se ha considerado dentro de esta investigación la importancia de explicar brevemente la sentencia que dio origen a este nuevo derecho, teniendo, además, en cuenta que fue en España donde por primera vez se empezó a hablar del derecho al olvido como un derecho independiente del derecho a la intimidad, pero íntimamente relacionado tanto con éste como con el derecho a la protección de datos personales.

Los hechos de esta STJUE son los siguientes: "El 5 de marzo de 2010, el Sr. Costeja González, de nacionalidad española y domiciliado en España, presentó ante la AEPD una reclamación contra La Vanguardia Ediciones, S.L., que publica un periódico de gran difusión, concretamente en Cataluña (en lo sucesivo, "La Vanguardia”), y contra Google Spain y Google Inc. Esta reclamación se basaba en que, cuando un internauta introducía el nombre del Sr. Costeja González en el motor de búsqueda de Google (en lo sucesivo, "Google Search"), obtenía como resultado vínculos hacia dos páginas del periódico 'La Vanguardia', del 19 de enero y del 9 de marzo de 1998, respectivamente, en las que figuraba un anuncio de una subasta de inmuebles relacionada con un embargo por deudas a la Seguridad Social, que mencionaba el nombre del Sr. Costeja González. Mediante esta reclamación, el Sr. Costeja González solicitaba, por un lado, que se exigiese a 'La Vanguardia' eliminar o modificar la publicación para que no apareciesen sus datos personales, o utilizar las herramientas facilitadas por los motores de búsqueda para 
proteger estos datos. Por otro lado, solicitaba que se exigiese a Google Spain o a Google Inc. que eliminaran u ocultaran sus datos personales para que dejaran de incluirse en sus resultados de búsqueda y dejaran de estar ligados a los enlaces de 'La Vanguardia'. En este marco, el Sr. Costeja González afirmaba que el embargo al que se vio sometido en su día estaba totalmente solucionado y resuelto desde hace años y carecía de relevancia actualmente".

Se trata de un supuesto relacionado con el tema de la protección de datos personales, en la que sobre todo analiza la Directiva 95/46, aunque debido a la relación que tiene esto con el derecho a la intimidad personal es conveniente reproducir las siguientes líneas de esta cuestión prejudicial: "El Tribunal de Justicia ya ha declarado que las disposiciones de la Directiva 95/46, en la medida en que regulan el tratamiento de datos personales que pueden atentar contra las libertades fundamentales y, en particular, contra el derecho a la intimidad, deben ser interpretadas a la luz de los derechos fundamentales que, según reiterada jurisprudencia, forman parte de los principios generales del Derecho cuyo respeto garantiza el Tribunal de Justicia y que están actualmente recogidos en la Carta (véanse, en particular, las sentencias Connolly/Comisión, C-274/99 P, EU:C:2001:127, apartado 37, y ÖsterreichischerRundfunk y otros, EU:C:2003:294, apartado 68). De este modo, el artículo 7 de la Carta garantiza el respecto de la vida privada, mientras que el artículo 8 de la Carta proclama expresamente el derecho a la protección de los datos personales. Los apartados 2 y 3 de este último precisan que estos datos se tratarán de modo leal, para fines concretos y sobre la base del consentimiento de la persona afectada o en virtud de otro fundamento legítimo previsto por la ley, que toda persona tiene derecho a acceder a los datos recogidos que le conciernan y a obtener su rectificación y que el respeto de estas normas estará sujeto al control de una autoridad independiente. Aplican estos requisitos, en particular, los artículos 6, 7, 12, 14 y 28 de la Directiva 95/46"35.

Este asunto es uno de los más relevantes sobre los que ha resuelto el Tribunal de Luxemburgo en los últimos años, ya que está íntimamente relacionado con otro de los derechos emergentes más comentados en el ámbito del Derecho de la Información, a raíz de la aparición de Internet, como es el derecho al olvido. A raíz de este pronunciamiento, el TJUE ha establecido, muy acertadamente, que este derecho, tan íntimamente relacionado con el derecho a la protección de datos personales, tiene que ser tenido en cuenta en el mundo virtual, porque los

35 STJUE del 13 de mayo de 2014, Caso Google v. Costeja González, Fundamentos 68 y 69. 
buscadores de Internet no se pueden convertir en bancos de datos sobre la vida privada de las personas.

En este punto es importante aclarar que el derecho al olvido digital en España, así como en un gran número de países de la Unión Europea, se está configurando como una manifestación del derecho a la protección de datos personales (una de las grandes excepciones es el caso de Francia, donde se está produciendo una ejemplar construcción del núcleo de garantía susceptible de protección, en donde se contemplan aspectos relacionados con los datos personales, así como con la intimidad). Tal como se está produciendo su configuración, tanto a nivel legislativo como jurisprudencial, se está produciendo, de manera bastante desacertada, un alejamiento respecto del derecho fundamental a la intimidad. Esto es así desde el momento en el que la información no tiene que ser eliminada de la fuente de origen, sino simplemente desindexada. No obstante, por no ser este el tema concreto de estas páginas, se sugiere acudir a bibliografía ${ }^{36}$ concreta en este tema para profundizar sobre esta cuestión.

\section{ConClusiones}

El ordenamiento jurídico multinivel que actualmente está vigente en Europa, en el ámbito de los derechos fundamentales, ha producido modificaciones respecto del contenido protegible de los derechos fundamentales en los ordenamientos jurídicos nacionales, aunque siempre bajo la premisa de que no existen derechos fundamentales absolutos. Los derechos fundamentales no pueden, ni deben, ser ilimitados, sino que todos están sujetos a limitaciones.

Por lo tanto, el resultado de este proceso se ha plasmado en una ampliación del contenido protegible del derecho a la intimidad dentro de España, ya que desde la posición europea se abarca un gran espectro que anteriormente no se contemplaba en dicho país.

En el ámbito del Consejo de Europa, los tribunales españoles han interpretado los derechos fundamentales de la Constitución, a la luz de su artículo 10.2, aplicando los mandatos del Convenio, incluyendo el referido a la fuerza de cosa interpretada de la jurisprudencia del TEDH. Ello se ha traducido en una labor interpretativa que en algún caso ha venido a suplir deficiencias de la regulación legislativa, y ha asegurado la protección de los derechos del Convenio. Se ha

36 Ver manuales de Simón Castellano y Azurmendi. 
producido así un dialogo entre tribunales que ha dado como resultado que el Derecho vivo se ajuste a los niveles exigidos por el TEDH.

Por otro lado, es importante subrayar las similitudes que existen entre lo recogido por el CEDH y lo protegido por la $\mathrm{CE}$, ya que ambos textos jurídicos parten de la misma idea básica: cada individuo tiene derecho a delimitar las zonas de su vida que quiere mantener alejadas de las miradas indiscretas, pero en la configuración europea el concepto es mucho más amplio, porque afecta tanto al ámbito interno como al externo de las personas.

Por lo tanto, es más dilatado porque engloba a diferentes derechos relacionados con el individuo como son la vida privada, la vida familiar, el respeto al domicilio, el respeto a la correspondencia, el derecho a la sexualidad, etc. Dentro del ordenamiento jurídico español se trata de un concepto abierto, además de vinculado a la doctrina del Tribunal Constitucional, que a su vez ha tenido muy presente la jurisprudencia que a este respecto ha emitido tanto el Tribunal de Luxemburgo como el de Estrasburgo, debido al constitucionalismo multinivel que actualmente está presente en España.

En el caso de la legislación y la jurisprudencia de la Unión Europea, también han influido en la definición del derecho a la intimidad, especialmente en todo lo relativo a la separación de éste como derecho autónomo respecto de la protección de datos personales, así como del derecho al olvido.

Es importante tener presente que los textos tanto nacionales como internacionales que se encargan del reconocimiento y la protección de los derechos humanos son instrumentos vivos, cuya interpretación tiene que acompañar la evolución de los tiempos y las condiciones de vida actuales. Debido a ello, tanto el Tribunal Constitucional español, como el TEDH y el TJUE, deben tener en cuenta los nuevos retos que demanda la sociedad relativos a los nuevos contenidos que debe proteger el derecho a la intimidad personal y familiar.

En definitiva, España y Europa, Europa y España son dos ordenamientos jurídicos con vigencia simultánea y complementaria, ya que los ordenamientos jurídicos nacionales han sido "atravesados" por la jurisprudencia de los Tribunales de Luxemburgo y Estrasburgo, así como por el Derecho originario y derivado de la Unión Europea.

\section{BiBLIOGRAFÍA CITADA}

Aguilar Cavallo, Gonzalo (2015): “El diálogo judicial multinivel”, en Núnez Poblete, Manuel Antonio, La internacionalización del Derecho Público (Santiago de Chile, Thomson Reuters), pp. 277-314. 
Alonso GarCía, Ricardo (2017): “Análisis crítico del veto judicial en la Unión Europea al CEDH en el Dictamen 2/13, de 18 de diciembre de 2014", en Ugartemendia Eceizabarrena, Juan Ignacio y Labayle, Henri (dirs.), La tutela judicial de los derechos fundamentales en el espacio de libertad, seguridad y justicia de la Unión Europea (País Vasco, Instituto Vasco de Administración Pública), pp. 142-173.

Alonso García, Ricardo (2015): "Sobre la adhesión de la UE al CEDH (o sobre cómo del dicho al hecho, hay un gran trecho)", Revista española de Derecho Europeo, (No 53), pp. 11-16.

Azurmendi, Ana (2014): “Por un 'derecho al olvido' para los europeos: Aportaciones jurisprudenciales de la Sentencia del Tribunal de Justicia europeo del caso Google Spain y su recepción por la Sentencia de la Audiencia Nacional española de 29 de diciembre de 2014”, en Revista de Derecho Político, UNED, (núm. 29, ), pp. 273-310.

Carrillo Salcedo, Juan Antonio (2003): El Convenio Europeo de Derechos Humanos (Madrid, Editorial Tecnos).

Casino Rubio, Miguel (2013): "López Ostra C. España (STEDH de 9 de diciembre de 1994): La contaminación ambiental y el derecho a la vida privada y familiar”, en Alcácer Guirao, Rafael, Beladíez Rojo, Margarita y Sánchez Tomás, José Miguel (coords.), Conflicto y diálogo con Europa. Las condenas a España del Tribunal Europeo de Derechos Humanos (Navarra, Editorial Thomson Reuters), pp. 419- 442.

DíeZ DE Velasco, Manuel (2017): Las organizaciones internacionales (16a edición) (Madrid, Editorial Tecnos).

Escobar Hernández, Concepción (2015): “La Unión Europea”, en Escobar Hernández, Concepción (coord.), Instituciones de la Unión Europea (Valencia, Editorial Tirant lo Blanch), pp. 31-48.

García VÁzQuez, Sonia (2015): "El derecho constitucional a la protección de la intimidad familiar: La impronta garantista de la jurisprudencia del Tribunal Europeo de Derechos Humanos", Anuario da Facultade de Dereito da Universidade da Coruña (No19), pp. 261-281.

Gómez SÁnchez, Yolanda (2008): Derecho constitucional europeo (Madrid, Editorial Sanz y Torres).

González Pascual, Maribel (2013): "El CEDH como parte del Derecho Constitucional europeo”, en Queralt Jiménez, Argelia (coord.), El Tribunal de Estrasburgo en el espacio judicial europeo (Madrid, Thomson Reuters-Aranzadi), pp. 109-130. 
Guasch Portas, Vicente y Soler Fuensanta, José Ramón (2015): “El derecho al olvido en internet", Revista de Derecho UNED (No 16), pp. 989-1005.

López Guerra, Luis María (2013): "El diálogo entre el Tribunal Europeo de Derechos Humanos y los tribunales españoles. Coincidencias y divergencias”, en Teoría y Realidad Constitucional (No 32), pp. 139-158.

Mangas Martín, Araceli (2008): "El compromiso con los derechos fundamentales", en Mangas Martín, Araceli y Norberto González, Luis (coords.), Carta de los derechos fundamentales de la Unión Europea: comentario artículo por artículo (Bilbao, Fundación BBVA), pp. 29-76.

Marcos Martín, Teresa (2015): "El Tribunal de Justicia de la Unión Europea”, en Escobar Hernández, Concepción (coord.), Instituciones de la Unión Europea (Valencia, Editorial Tirant lo Blanch), pp. 157-170.

MARICA, Andrea (2013): Unión Europea y el perfil constitucional de su Tribunal de Justicia (Navarra, Editorial Thomson Reuters).

Maté Sauté, Loreto Carmen (2017): “¿Qué es realmente el derecho al olvido?”, Revista de Derecho Civil (Volumen III, No 2), pp. 187-222.

Medina Guerrero, Manuel (2005): La protección constitucional de la intimidad frente a los medios de comunicación (Valencia, Editorial Tirant Monografías 352).

Mellado Prado, Pilar (2009): "El proceso de integración europea", en Mellado Prado, Pilar, Linde Paniagua, Enrique y Gómez de Liaño Fonseca-Herrero, Marta, Instituciones de derecho comunitario (Madrid, Editorial Colex).

Moreno Bobadilla, Ángela (2017): Intimidad y menores (Madrid, Centro de Estudios Políticos y Constitucionales).

Moreno Bobadilla, Ángela (2015): "El derecho a la intimidad en España”, en Revista Ars Boni et Aequi, Año 12, Número 1, pp. 33-57.

Nogueira Alcalá, Humberto (2014): Derechos fundamentales, bloque constitucional de derechos, diálogo interjurisdiccional y control de convencionalidad (México, Editorial UBIJUS).

NoreÑa Salto, José Ramón (2002): “Libertad de información y derecho a la intimidad y propia imagen. Especial referencia a determinados delitos y al proceso de menores", en Revista Estudios Jurídicos, pp. 53-72.

Ojinaga Ruiz, Rosario (2015): "El proceso de integración europea”, en Escobar Hernández, Concepción (coord.), Instituciones de la Unión Europea (Valencia, Editorial Tirant lo Blanch), pp. 17-29.

Otaegui Aizpúrua, Idioa (2014): "Artículo 7: El derecho al respeto a la vida privada y familiar o el derecho a que nadie se inmiscuya en la esfera privada de las personas", en Ordeñana Guruzga, Ixusko (dir.), La carta de los derechos 
fundamentales de la Unión Europea y su reflejo en el ordenamiento jurídico español (Navarra, Editorial Thomson Reuters), pp. 145-160.

Rebollo Delgado, Lucrecio (2005): El derecho fundamental a la intimidad (Madrid, Editorial Dykinson).

Ripol Carulla, Santiago (2007): El sistema europeo de protección de los derechos humanos y el derecho español (Barcelona, Editorial Atelier Libros Jurídicos).

Ruiz Miguel, Carlos (2003): "El derecho a la protección de los datos personales en la Carta de Derechos Fundamentales de la Unión Europea”, en Herrero de la Fuente, Alberto A., La Carta de los Derechos Fundamentales de la Unión Europea. Una perspectiva plurisdisciplinar (Zamora, Cuadernos del Instituto Rei Afonso Henriques de Cooperación Transfronteriza), pp. 173-210.

Ruiz De Miguel, Carlos (1994): El derecho a la protección de la vida privada en la jurisprudencia del Tribunal Europeo de Derechos Humanos (Madrid, Editorial Civitas).

Santolaya Machetti, Pablo (2009): "El derecho a la vida privada y familiar (un contenido notablemente ampliado del derecho a la intimidad)", en García Roca, Javier y Santolaya Machetti, Pablo (coords.), La Europa de los Derechos. El Convenio Europeo de Derechos Humanos (2a edición) (Madrid, Editorial del Centro de Estudios Políticos y Constitucionales), pp. 487-508.

Sarmiento, Daniel, Miéres Miéres, Luis Javier y Presno Linera, Miguel (2007): Las sentencias básicas del Tribunal Europeo de Derechos Humanos, Estudio y jurisprudencia (Navarra, Editorial Civitas).

Simón Castellano, Pere (2015): El reconocimiento del derecho al olvido digital en España y en la UE. Efectos tras la sentencia del TJUE de mayo de 2014 (Barcelona, Editorial Bosch).

Torres Ugena, Nila (2015): "Las fuentes del derecho de la Unión”, en Escobar Hernández, Concepción (coord.), Instituciones de la Unión Europea (Valencia, Editorial Tirant lo Blanch), pp. 225-237.

\section{NORMAS JURÍDICAS CITADAS}

Reglamento (UE) 2017/679 relativo a la protección de las personas físicas en lo que respecta al tratamiento de sus datos personales y a la libre circulación de estos datos.

Tratado de Lisboa, del 13 de diciembre de 2007.

Directiva 58/2002/CE del Parlamento Europeo y del Consejo, de 12 de julio de 2002. 
Carta de Derechos Fundamentales de la Unión Europea, del 7 de diciembre del 2000.

Ley Orgánica 1/1982, de Protección Civil del Derecho al Honor, a la Intimidad Personal y Familiar y a la Propia Imagen, de 5 de mayo de 1982.

Constitución Española, del 6 de diciembre de 1978.

Convenio Europeo de Derechos Humanos, del 4 de noviembre de 1950.

Estatuto del Consejo de Europa, del 5 de mayo de 1949.

\section{JURISPRUDENCIA CITADA}

STJUE C-131/12, de 13 de mayo de 2014.

STEDH Caso Moreno Gómez c. España, de 16 de noviembre de 2004.

STC 1/2004, de 13 de febrero.

STJCE Mary Carpenter c. Secretary of State for the Home Department, de 11 de julio de 2002.

STEDH Caso Valenzuela Contreras c. España, de 30 de julio de 1998.

STEDH Caso López Ostra c. España, de 9 de diciembre de 1994.

STJCE Erich Stauder v. Stadt Ulm-Sozialamt, de 12 de noviembre de 1969. 